\title{
Contingent attentional capture or delayed allocation of attention?
}

\author{
ROGER W. REMINGTON \\ NASA Ames Research Center, Moffett Field, California \\ CHARLES L. FOLK \\ Villanova University, Villanova, Pennsylvania \\ and \\ JOHN P. MCLEAN \\ University of Queensland, Queensland, Australia
}

\begin{abstract}
Under certain circumstances, external stimuli will elicit an involuntary shift of spatial attention, referred to as attentional capture. According to the contingent involuntary orienting account (Folk, Remington, \& Johnston, 1992), capture is conditioned by top-down factors that set attention to respond involuntarily to stimulus properties relevant to one's behavioral goals. Evidence for this comes from spatial cuing studies showing that a spatial cuing effect is observed only when cues have goal-relevant properties. Here, we examine alternative, decision-level explanations of the spatial cuing effect that attribute evidence of capture to postpresentation delays in the voluntary allocation of attention, rather than to on-line involuntary shifts in direct response to the cue. In three spatial cuing experiments, delayed-allocation accounts were tested by examining whether items at the cued location were preferentially processed. The experiments provide evidence that costs and benefits in spatial cuing experiments do reflect the on-line capture of attention. The implications of these results for models of attentional control are discussed.
\end{abstract}

In many organisms, including humans, reflexive orienting responses provide a means of alerting the organism to potentially significant external events. In this exogenous (Posner, 1980) mode of orienting, spatial attention shifts rapidly and involuntarily to the external stimulus that triggers the response, thus providing an adaptive means of controlling attention independent of the current task goals. In essence, it constitutes an interrupt system that allows the organism to engage in goal-directed, endogenous allocation of attention without the need to deliberately monitor for significant unexpected events. Current theories of attentional control support both endogenous and exogenous modes of human orienting by including bottom-up pathways, whereby an external stimulus can summon attention, and top-down pathways, whereby task goals can direct attention (e.g., Bundesen, 1990; Cave \& Wolf, 1990; Treisman \& Sato, 1990; Wolf, Cave, \& Franzel, 1989).

Exogenous orienting can be strongly involuntary, so that attention will be captured by an external event even when subjects have strong incentives to inhibit the response (Folk \& Remington, 1996; Remington, Johnston, \& Yan-

This work was supported in part by NSF Grant BCS-9817673 to C.L.F. The authors thank Kyle Cave, Jeffery Mounts, Eric Ruthruff, Maria Stone, Steven Yantis, and an anonymous reviewer for helpful comments on earlier drafts. Correspondence concerning this article should be addressed to R. W. Remington, NASA Ames Research Center, MS262-4, Moffett Field, CA 94035 (e-mail: rremington@mail.arc.nasa.gov). tis, 1992). Similarly, salient external events have been shown to capture attention despite instructions to (endogenously) attend to a different location, evidence that bottom-up pathways dominate top-down ones (e.g., Müller $\&$ Rabbitt, 1989). The strongly involuntary nature of exogenous orienting has contributed to the view that attentional capture is purely stimulus driven. That is, capture is an involuntary response to properties of the stimulus array, such as abrupt luminance transients (Yantis \& Jonides, 1984, 1990), salient stimulus differences (Theeuwes, 1991, 1992), or the recent history of the array (e.g., the "new" objects of Yantis \& Hillstrom, 1994). Attentional capture in such stimulus-driven accounts is insensitive to the current behavioral goals of the organism, so that there is little or no role for mediation by top-down control pathways.

However, the results of Folk, Remington, and Johnston (1992) suggest a more active role for top-down control in mediating or conditioning the involuntary capture response. In a series of spatial cuing experiments (Folk et al., 1992, Experiment 4; Folk, Remington, \& Wright, 1994), it was found that a stimulus (cue) presented prior to a target stimulus would capture attention only if it contained the elementary properties that defined the target. Thus, abrupt onsets captured attention when subjects were set to process targets defined by an abrupt onset, but not when the target was defined as a color singleton. Folk et al. (1992; see also Folk, Remington, \& Johnston, 1993; Folk et al., 1994) theorized that task goals condi- 
tion attention by defining which features will elicit the involuntary attentional shift. They referred to this as contingent involuntary orienting. In the contingent orienting account, task goals determine, in part, what features of the environment are of immediate importance. Topdown pathways transmit relevant feature information to attentional control settings, which then condition attention to respond involuntarily to stimuli presenting these features. The appearance of a stimulus with those properties will elicit a rapid, involuntary shift of attention. Rather than involuntary control dominating voluntary control in the presence of specific stimulus properties, topdown mechanisms incorporate behavioral goals into a program that permits a context-dependent involuntary attentional response. Recent visual search experiments have provided support for the role of top-down factors, consistent with the contingent orienting account (Theeuwes \& Burger, 1998; Yantis \& Egeth, 1999).

Despite these recent visual search results, support for top-down mediation of attentional capture comes primarily from spatial cuing experiments, whereas evidence for stimulus-driven capture comes primarily from visual search experiments. Whenever theoretical differences correspond closely to paradigm differences, it becomes important to examine the assumptions that relate empirical outcomes to theory. In spatial cuing experiments, the presence of a cue validity effect is taken as evidence that the cue drew attention to itself (and consequently, its location). In this paper, we ask whether it is possible to account for cuing effects without assuming that the cue elicited a shift of attention. Such an account would present a potential problem for contingent involuntary orienting account, since that theory postulates a set of mental operations underlying capture that go beyond the empirical observation of a cuing effect. Specifically, contingent orienting assumes that attentional capture reflects an online reallocation in response to properties of the cue. In addition, use of the spatial cuing paradigm is widespread, making it important to know whether the common interpretation of results in this paradigm rests on assumptions that generalize across a wide range of stimulus conditions and task demands.

\section{The Control of Attention by Spatial Cues}

In a typical spatial cuing experiment, a cue is flashed briefly around one of several potential target locations prior to presentation of the target character. On valid trials, the cue occurs at the location of the subsequent target; on invalid trials, it occurs at a nontarget location. A cuing effect is obtained when response times on invalid trials are slower than those on valid trials. This pattern of results (cuing effect) is assumed to arise because the cue has drawn attention to its location. The response time difference is presumed to occur because, on valid trials, attention will already be focused on the target location when the target is presented, whereas on invalid trials, it will be focused on a nontarget location. The cuing effect then reflects the misallocation of attention on invalid trials. Folk et al. (1992; Folk et al., 1994) relied on this logic to determine the cue-target relationships that will produce capture. For example, a significant cuing effect obtained when color cues were paired with color targets. In that condition, the cue consisted of a set of four dots briefly flashed around all four potential target locations. Three of the sets were white, and one set was red (the cue). In the target frame, an alphanumeric character was presented in each of the four boxes. Three were white, and one was red (the target). This result was interpreted as evidence that an attention shift to the location of the red cue was initiated prior to the onset of the target frame. In contrast, no cuing effect was obtained with color singleton targets when the cue was an abrupt luminance onset occurring around a single location. This was taken as evidence that the cue failed to elicit a shift of attention.

However, evidence for capture in Folk et al. (1992) came only from conditions in which it was difficult to discriminate the cue from the target. For example, when the target is distinct from background characters in color only, color becomes the property on which the target is located (target-finding property). When both the cue and the target were red color singletons (e.g., Folk et al., 1992; Folk et al., 1994), on invalid trials the target-defining property (red) was present at both the cue and the target locations, whereas on valid trials red occurred only at the target location. This raises the possibility that the increased response times reflected the increased difficulty of deciding where to allocate attention. According to this account, attention shifts to the target location once sufficient evidence for the target-finding property has accrued. On invalid trials, both the cue location and the target location contain evidence of the finding property. More evidence will need to be collected to determine which location to attend to, resulting in an increase in response time on invalid trials. To illustrate, assume that beginning with cue onset, evidence accrues as to the location containing the target-finding property (red). On valid trials, a decision can be made quickly, since both the cue and the target provide consistent evidence about the location of the finding property. On invalid trials, initial evidence from the cue suggests one location, evidence from the target another. Even when the evidence from the cue is insufficient to trigger an attention shift, it adds noise to the decision process, delaying the allocation of attention. According to this account, cuing effects can occur without spatial attention's being shifted to the cued location. Indeed, attention is not really captured, but simply delayed. The logic is similar to objections we have raised about attributing all instances of interference from irrelevant singletons in visual search to shifts of spatial attention (Folk \& Remington, 1998). The delayedallocation account posits continued information accrual across the cue-target interval, which typically lasts on 
the order of $250 \mathrm{msec}$. Accumulation and retention of evidence over this period is well within the measured capabilities for sensory stores (see, e.g., Sperling, 1960).

Delayed allocation presents a potential problem for contingent orienting, which assumes an immediate response to the presentation of a stimulus with properties for which attention has been set. At present, there is no direct evidence that would distinguish between the online allocation and the decision-level accounts of the cuing effect. However, the two accounts make different predictions about the processing of items at the cued location. Since the processing of stimulus information is enhanced at attended locations, an on-line shift of attention to the cued location should facilitate the processing of stimuli that occur at that location, relative to items at noncued locations. Since a decision-level account entails no shift of attention, only delayed allocation, processing of items at cued locations should not differ from that of items at noncued locations. Thus, the delayed-allocationaccount can be distinguished from the contingent capture account by testing for the presence or absence of enhanced identity processing at the invalid cued location.

\section{Logic of the Experiments}

In the remainder of the paper, we describe a series of spatial cuing experiments designed to test whether the capture of attention entails the processing of the identity of the item at the cued location. A spatial cue directs subjects' attention to a location that, on some trials, contains a nontarget character whose identity is incompatible with the response to the target. According to the delayed-allocation hypothesis, target response times should be unaffected by this incompatibility, since attention is never allocated on-line in response to the cue, but is delayed by the presence of the finding property (color) at the cued location. In contrast, the contingent orienting account predicts a substantial effect of compatibility for foils that occur at the cued location as a result of attention's being shifted to the cued location on line.

\section{EXPERIMENT 1}

The design of Experiment 1 attempted to achieve four goals that were necessary to characterize the processing of nontarget items at a cued location. First, to ensure that we would get a strong cuing effect, we used the color singleton cue-target condition of Folk et al. (1992), which has been used to demonstrate contingent attentional capture. Second, to measure the processing of nontarget characters, we varied the compatibility of one of the nontarget characters by including in the target display a foil, one of the target characters (T or L) presented in the nontarget color (white). Interference from incompatible foils was used to assess whether identity information was being processed. Third, to test whether the identity of the character at the cued location was preferentially processed, the target display included two neutral characters (E and $\mathrm{F}$ ), not members of the target set, $\mathrm{T}$ and $\mathrm{L}$. If attention were shifted on line in response to the cue, incompatible foils should produce more interference when they occurred at the cued location than at a noncued location. Fourth, to determine whether any observed interference reflects a sustained commitment of attention or a transitory effect, we included three stimulus onset asynchronies (SOAs). Transitory effects could result from fading in iconic memory (delayed-allocation model) or rapid reallocation of attention (contingent orienting model). In effect, our method combines the critical elements of the flanker effect studies (e.g., Eriksen \& Hoffman, 1973; Kramer \& Jacobson, 1991) with a manipulation designed to control the locus of spatial attention.

\section{Method}

Subjects. Twenty-four subjects from the NASA Ames Research Center subject pool participated in the study for partial credit. The subjects were recruited from local universities and community colleges. All the subjects were between 18 and 30 years of age and had normal or corrected-to-normal vision.

Apparatus. Stimulus presentation was controlled by an ACER Pentium computer. The stimuli were presented on a 14-in. NEC Multisync 4FG monitor set at a comfortable brightness level. The monitor was placed at eye level approximately $60 \mathrm{~cm}$ from the subject. No attempt was made to stabilize the head or to otherwise control precisely for viewing distance.

Stimuli. A fixation display, a cue display, and a target display were presented in succession on each trial. Figure 1 shows the displays and the sequence of events. The fixation display consisted of a fixation cross in the center of the screen, surrounded by four boxes. The boxes were placed above, below, left, and right of fixation, at the end points of an imaginary cross, centered on the fixation cross. The cross subtended approximately $0.25^{\circ}$ of visual angle horizontally and vertically. Each box subtended approximately $1.8^{\circ}$ of visual angle horizontally and vertically and was positioned approximately $3.2^{\circ}$ from the center of the fixation cross. The boxes and the fixation cross were light gray against the black background of the monitor.

The cue display consisted of the fixation display with the addition of sets of four small circles arrayed in a diamond conf iguration around each of the four boxes. The diameter of each small circle was approximately $0.2^{\circ}$ of visual angle placed approximately $0.2^{\circ}$ from the edges of each box. Three sets of circles were light gray. The fourth, the cue, was a red set of circles surrounding one of the locations.

The target display consisted of the fixation display with the addition of a single letter in the center of each box. The letters subtended approximately $0.9^{\circ}$ of visual angle vertically and approximately $0.6^{\circ}$ horizontally. The three nontarget letters were presented in the same light gray as in the cue display, the single target in the same red as the cue. The SOA between the onset of the cue display and the onset of the target display was 100,250 , or $450 \mathrm{msec}$.

Design. The target displays contained the red target character among three white nontarget characters. Of the three nontarget characters, one was always an E, and one was always an F. For compatible displays, the fourth character was a foil identical to the target. For incompatible displays, the fourth character was the foil character associated with the competing response. For no-foil displays, the fourth character was one of the neutral characters (E or F), chosen randomly.

There were two types of invalid trials, neutral and foil. On neutral trials, the stimulus at the cued location was one of the neutral characters (E or F). On foil trials, it was one of the target characters ( $\mathrm{T}$ or L), printed in white. Likewise, when the cue was valid, the target character appeared at the cued location. For consistency, we indicate cue location by the type of character that occurred there: target, 
TARGET DISPLAY

(50 MSEC)

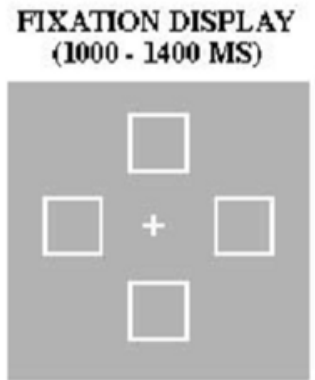

CUE DISPLAY (50 MS)

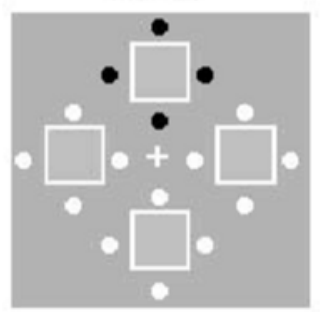

FIXATION DISPLAY (100 MS)

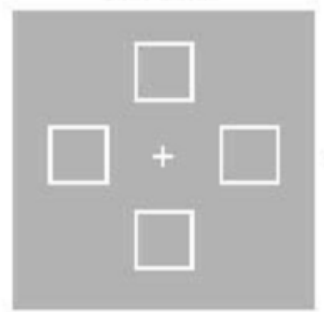

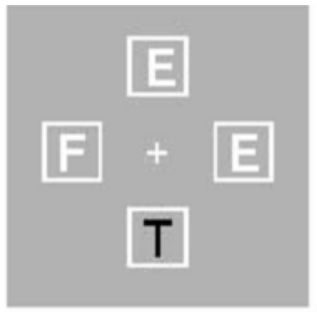

INVALID $\mathrm{P}=.75$

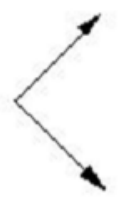

VALID $\mathbf{P}=.25$

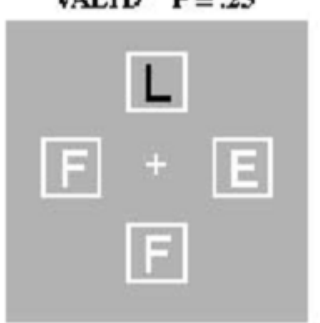

Figure 1. The sequence and timing of events within a trial in Experiment 1. Dark elements represent red items, bright elements represent white items. The target displays are representative of neutral trials, in which no foil character appears.

neutral, or foil. Figure 2 shows representative displays for compatible and incompatible trial types in target, neutral, and foil cue location conditions. Figure 1 shows displays associated with no-foil trials.

The experiment consisted of 360 trials. Table 1 shows how the trials were distributed among the nine cells created by crossing cue location with foil compatibility. The presence of no-foil trials means that only eight of the nine cells could be tested. All the conditions were balanced with respect to SOA and target identity (T or L). All 360 trials were generated, then randomized and divided into nine blocks of 40 trials each. Thus, each block contained a mixture of all the factors.

Procedure. The subjects read a set of written instructions, after which the experimenter explained the experiment again and answered questions. The experimenter stressed the need for fast but accurate responses and explicitly instructed subjects to ignore the "distractors" (cues) and the nontarget characters in the target display. Following this briefing, the subjects were tested in a practice block in a darkened sound-attenuated booth. The experimenter was present during practice to answer any questions and ensure that subjects understood the task. When the subject was ready, the experimenter left the booth, and the subject completed the experiment.

At the beginning of the experiment, the same set of instructions was presented on the computer screen as a reminder. After reading it, the subjects pressed a key to begin the experimental sequence. At the beginning of each block, two trials were chosen at random from the set of experimental trials and presented as practice trials. Practice trials and trials on which errors were made were presented again. Blocks began with the presentation of the set of four target location boxes, along with a central fixation cross. The beginning of the trial sequence was signaled by the blink of the fixation cross. The trial sequence is shown graphically in Figure 1. A fixation display was presented for a randomly chosen duration between 1,000 and $1,400 \mathrm{msec}$, followed by a 50 -msec presentation of the cue display, which contained the red cue surrounding one of the four boxes. The cue display was followed by a $50-\mathrm{msec}$ presentation of the fixation display. The target display was then presented for $50 \mathrm{msec}$. The subjects pressed one of two keys to indicate whether the red character was a $\mathrm{T}$ or an $\mathrm{L}$. If the response was correct, the next trial was presented after a 1,000 -msec intertrial interval. If the response was incorrect, the subjects were presented a brief tone, along with a 500msec presentation of the word ERROR in the middle of the screen. If a key other than the two response keys was pressed, the phrase WRONG KEY was displayed for $500 \mathrm{msec}$. The trial sequence was then begun after a 1,000-msec intertrial interval. At the end of each block, response time and error feedback was given. If the error rate was high, a message was presented instructing the subject to reduce the number of errors. The subjects were informed that they could rest for as long as they chose between blocks.

\section{Results $^{1}$}

Cue validity effect. Figure 3 plots response times for compatible, incompatible, and no-foil display types as a function of cue location separately for each SOA. The effect of cue validity (cuing effect) was assessed by comparing performance at target and neutral cue locations. A repeated measures analysis of variance (ANOVA) was conducted on the mean correct response times, with cue location (target or neutral), trial type (compatible, incom- 
TARGET
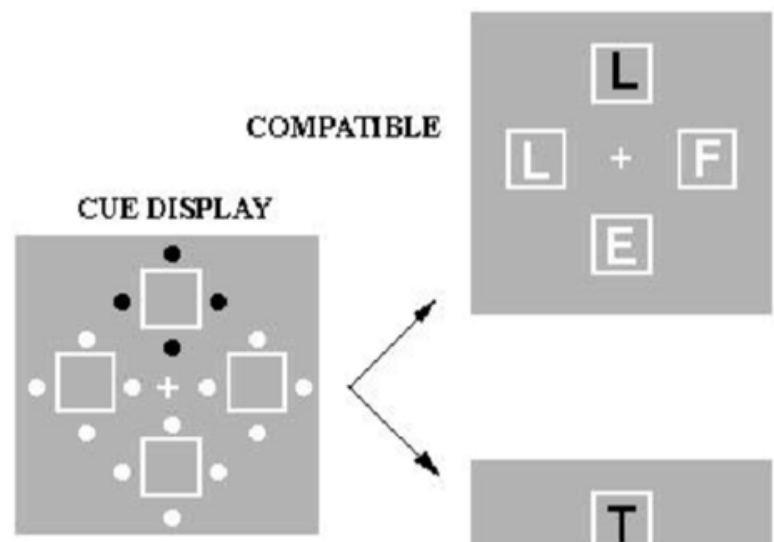

INCOMPATIBLE

Targets:

Neutrals:

Foils:

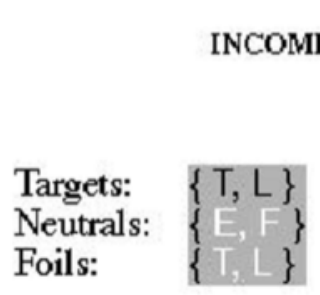

NEUTRAL
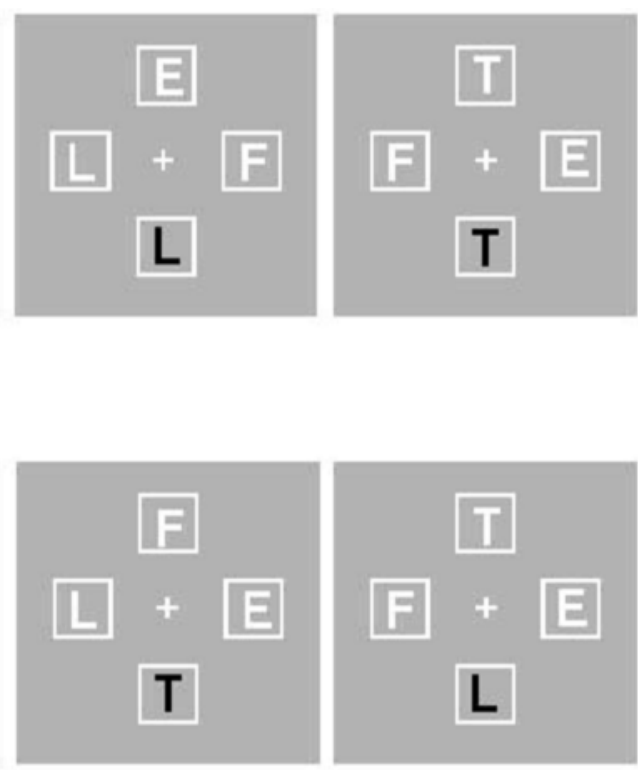

Figure 2. Representative displays from compatible and incompatible foil conditions (top and bottom rows, respectively) in Experiment 1 for all three cue locations: target, neutral, and foil (columns).

patible, or no-foil), and SOA $(100,250$, or $450 \mathrm{msec})$ as factors. There were significant main effects of cue location $[F(1,23)=36.86, p<.001]$, trial type $[F(2,46)=$ $9.43, p<.001]$, and SOA $[F(2,46)=9.25, p<.001]$. The SOA $\times$ cue location interaction $(F<1)$, the SOA $\times$ compatibility interaction $[F(4,92)=1.71, p<.2]$, and the three-way SOA $\times$ cue location $\times$ compatibility interaction $[F(4,92)=1.67, p<.2]$ did not approach significance.

Compatibility effects. A repeated measures ANOVA compared response times for compatible and incompatible foils at neutral and foil cue locations at each SOA. The analysis revealed significant main effects of cue location $[F(1,23)=12.12, p<.01]$, compatibility $[F(1,23)=$ $123.79, p<.001]$, and SOA $[F(2,46)=6.22, p<.01]$ and a significant interaction of compatibility and cue location $[F(1,23)=29.99, p<.001]$. The difference in response time between incompatible and compatible foils

Table 1

Number of Trials in Each Combination of Cue Location and Foil Compatibility Conditions for Experiment 1

\begin{tabular}{ccccc}
\hline & \multicolumn{3}{c}{ Target Display Type } & \\
\cline { 2 - 4 } Cue Location & Compatible & Incompatible & No Foil & Total \\
\hline Target & 36 & 36 & 18 & 90 \\
Neutral & 54 & 54 & & 108 \\
Foil & 54 & 54 & 54 & 162 \\
Total & 144 & 144 & 72 & 360 \\
\hline
\end{tabular}

was $15 \mathrm{msec}(477-462)$ in the neutral cue location condition, as compared with $42 \mathrm{msec}(501-459)$ in the foil cue location condition. The significant three-way interaction of cue location, compatibility, and SOA $[F(2,46)=$ $6.13, p<.01]$ reflected changes in the magnitude of the compatibility effect with SOA. The differences between compatible and incompatible characters at the foil cue location were 48,47 , and $31 \mathrm{msec}$ for SOAs of 100,250 , and $450 \mathrm{msec}$, respectively. A post hoc analysis (NeumanKeuls, alpha $=.01$ ) found the magnitude of the compatibility effect significant at all three SOAs, with the effect size at $450 \mathrm{msec}$ significantly less than the other two.

Error data. The error data are shown in the bottom of Figure 3. In general, errors follow the same pattern as response times, suggesting that the response time effects were not the result of a speed-accuracy tradeoff.

\section{Discussion}

The interaction of foil compatibility and cue location was exactly that predicted by the contingent involuntary orienting account. The size of the compatibility effect was significantly greater in the foil condition than in the neutral condition, clear evidence that the identity of the character at the cued location was processed to a greater degree than that of characters at noncued locations. Furthermore, this increase was due to increased interference from incompatible foils in the foil cue condition. The 

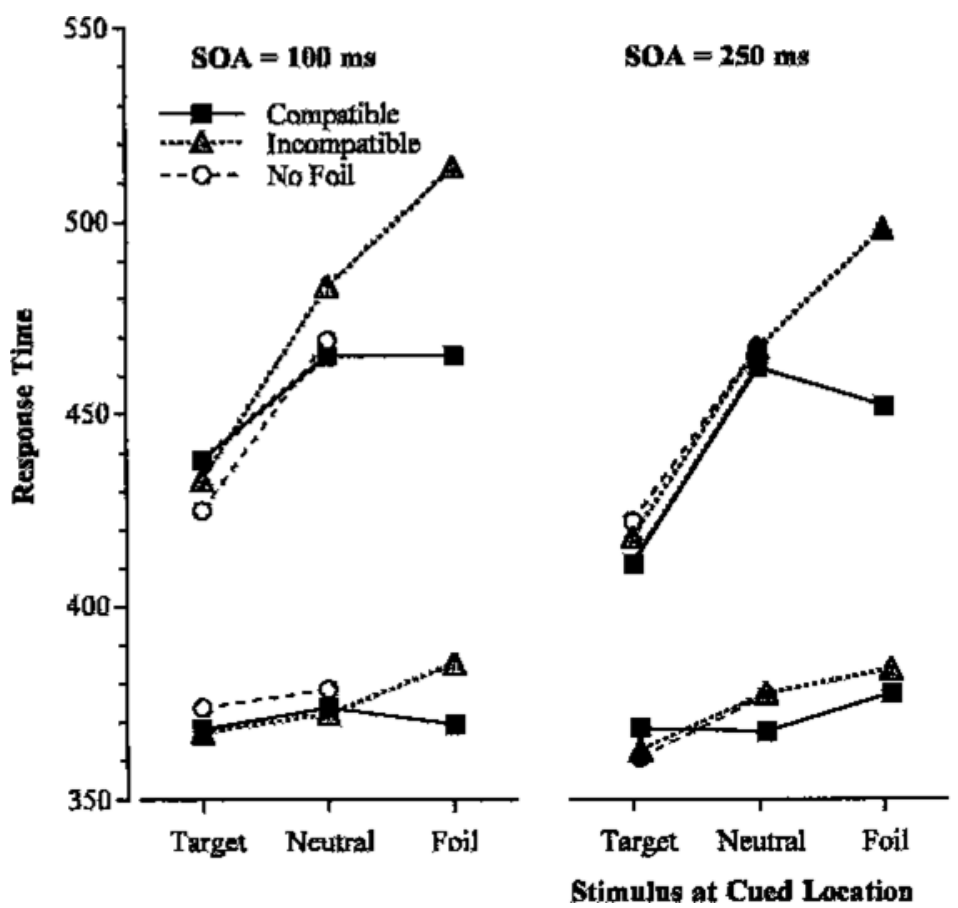

$\mathrm{SOA}=450 \mathrm{~ms}$

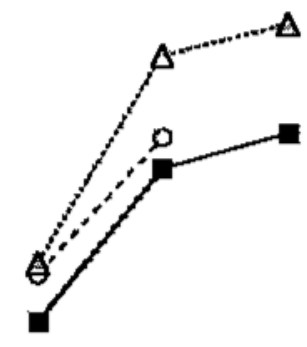

Figure 3. Target identification times (top row) and error rates (bottom row) for compatible, incompatible, and no-foil conditions at the three cue locations (target, neutral, and foil) at each of the three stimulus onset asynchronies in Experiment 1.

longest response times were associated with an incompatible foil at an invalid cue location. The intrusion of identity information from characters at invalid cue locations is inconsistent with the delayed-allocation account.

The delayed-allocation account also predicted a reduction in the size of the cuing effect with increasing SOA. The cuing effect can best be measured by comparing target and neutral conditions, for which the comparison is uncontaminated by compatibility effects (the interaction of cue location and compatibility was not significant for these two cue locations). Cuing effects at SOAs of 100,250, and $450 \mathrm{msec}$ were 40,48 , and $43 \mathrm{msec}$, respectively. Clearly, there is no support here for the delayed-allocation account. In short, no support for delayed allocation was found either in the compatibility effects or in the size of the cuing effect with SOA.

It is also important to note that lengthening the cuetarget SOA did not change the main pattern of results. A post hoc analysis (Neuman-Keuls, alpha $=.01$ ) revealed significant compatibility effects in the foil condition at all SOAs, although the effect was significantly reduced at the 450-msec SOA. This reduction did not result from a systematic trend toward decreased interference from incompatible foils at the cued location; those response times were 511, 495, and $496 \mathrm{msec}$ at SOAs of 100, 250, and $450 \mathrm{msec}$, respectively, as compared with 463,448 , and $465 \mathrm{msec}$ for compatible foils. Overall, there is no evidence to suggest that the longer SOA is associated with a decreased processing of items at the cued location. This strongly supports the on-line allocation of attention to the cue and suggests that the effects of attention on processing are not transitory. It is difficult to reconcile this sustained interference with the delayed-allocation model, in which no on-line shift of attention is presumed to occur. Within the context of on-line shifts of attention, as in contingent orienting, subjects could decide to shift quickly away from the cued location once they determine that it is not the target. The persistence noted here suggests either that attention is not shifted away or that the processing set in motion by the initial allocation continues independent of subsequent changes in attention allocation.

Another interesting outcome was that compatibility effects were not confined to the foil cue condition. A Neuman-Keuls post hoc analysis (alpha $=.05)$ showed significant compatibility effects in the neutral conditions (i.e., when a foil occurred at a noncued location). To some degree, then, identities of characters at locations other than target and cue were being processed. It is not clear why the attention filter is "leaky." Perhaps some degree of automatic processing is possible with such highly familiar alphanumeric characters. Nonetheless, the interaction of cue location and foil compatibility clearly indicates that the identities of characters at cued locations were being preferentially processed, inconsistent with the delayed-allocation account.

\section{EXPERIMENT 2}

The results of Experiment 1 support the on-line capture of attention by the irrelevant color cue and are inconsis- 
tent with a decision-level account of the cuing effect. Even stronger support for the on-line allocation could be provided by more direct evidence that the shift of attention occurred in close temporal proximity to the cue. To accomplish this, Experiment 2 measured the effects of a foil that appeared simultaneously with the onset of the cue display, rather than with the target display. The foil was presented briefly $(50 \mathrm{msec})$ and then pattern-masked. We reasoned that because the foil (1) appeared $150 \mathrm{msec}$ prior to the target display, (2) was masked, and (3) was presented for only $50 \mathrm{msec}$, its identity could influence response time only if attention were directed at its location in close temporal proximity to its presentation. Accounts that assume attention is shifted in response to cue onset, such as contingent capture, predict compatibility effects when the foil appears at the cued location and no effects when it appears at a noncued location. Decision-level accounts, such as the delayed-allocation model, on the other hand, predict no greater effect of compatibility in the foil condition, because there would be no differential allocation of attention at the time of foil presentation.

\section{Method}

Subjects. Fifteen undergraduate subjects from Villanova University participated in partial fulfillment of a course requirement. All had normal or corrected-to-normal visual acuity.

Apparatus. The stimuli were presented on a Princeton Graphics Systems Ultrasync monitor, controlled by a Zenith 286 microcomputer equipped with a Sigma Design, Color $400(680 \times 400)$ graphics board. The subjects viewed the monitor from a distance of $50 \mathrm{~cm}$ through lensless goggles attached to a porthole on the front of a viewing box.

Stimuli. The stimuli were identical to those used in the first experiment, with the following exceptions. Simultaneously with the onset of the cue display, a foil character was presented for $50 \mathrm{msec}$ in one of the four boxes, then was replaced by a $50-\mathrm{msec}$ presentation of masking characters in each of the four boxes. The foil character had the same dimensions and color as the foils used in the previous experiment. Masking characters consisted of short, vertical, horizontal, and diagonal line segments randomly distributed in an imaginary square subtending $0.6^{\circ} \times 0.6^{\circ}$ of visual angle. The target display consisted of the (red) target in one box and (white) neutral characters (E or F, chosen randomly) in the other three boxes.

Design and Procedure. The experiment consisted of eight blocks of 64 trials each. In each block of 64 trials, 16 trials were valid, 48 were invalid. Half the time the foil appeared at the cued location, half the time at one of the three noncued locations. As in the first two experiments, on half the trials the foil was compatible with the subsequent target, on half incompatible. All factors were fully crossed. All other features were identical to those in the previous experiments.

\section{Results and Discussion}

Figure 4 shows the effect of compatibility as a function of whether or not the foil occurred at the cued location. The results are plotted separately for valid and invalid trials. Compatibility effects were observed for both valid and invalid trials when the foil occurred at the cued location, but there was no effect of compatibility when the foil was at a noncued location.

A repeated measures ANOVA conducted on mean correct response times found significant main effects of foil

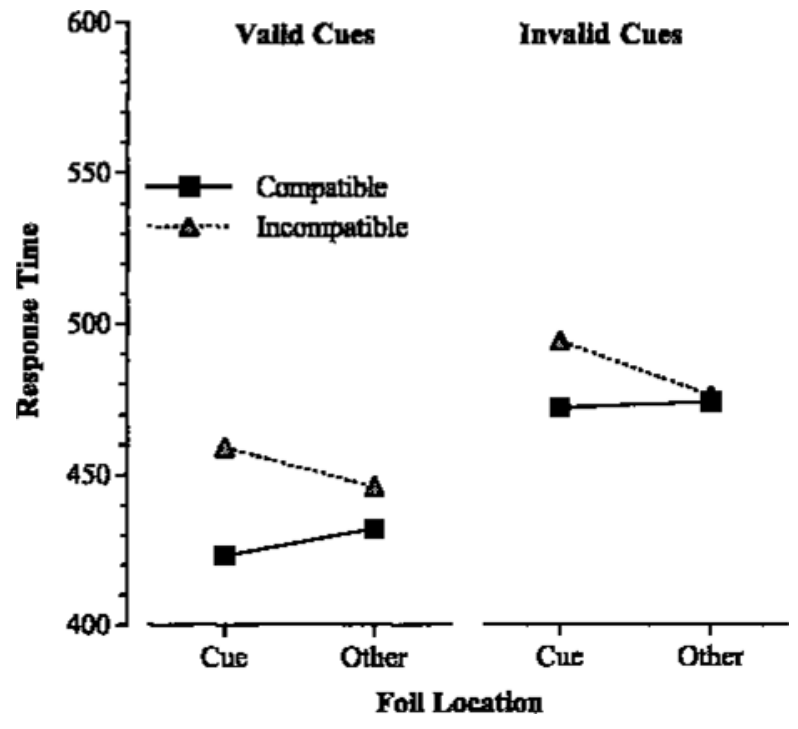

Figure 4. Target identification times (in milliseconds) as a function of foil location in Experiment 2.

compatibility $[F(1,14)=16.87, p<.001]$ and cue validity $[F(1,14)=9.88, p<.01]$. Importantly, there was a significant interaction between foil location (cue location, noncue location) and compatibility $[F(1,14)=10.44$, $p<.01]$. When the foil occurred at the cued location, mean response time for compatible and incompatible foils was 447 and 477 msec respectively $[F(1,14)=36.68, p<$ .001 ], as compared with 453 and $461 \mathrm{msec}$, respectively $[F(1,14)=1.59, p>.05]$, when the foil occurred at a noncued location. Consistent with the prediction of contingent orienting, foil compatibility affected response time only when it occurred at a cued location. This result strengthens the evidence for on-line allocation of attention in response to the cue by showing that characters presented briefly at the time of the cue, then masked, can affect target response time only when they occur at a cued location.

An ANOVA on error percentages revealed a significant effect only for cue validity $[F(1,14)=5.31, p<.05]$.

\section{EXPERIMENT 3}

Both previous experiments found increased interference from incompatible foils at the cued location, evidence that attention shifted on line in response to the presentation of the cue. To firmly establish the links between on-line shifts of attention and the observed compatibility effects, it is important to show that no such enhanced processing occurs when attention is not drawn to the cue. The contingent involuntary orienting account predicts that shifts of attention should not occur when the cue does not contain the target-finding property. Previous work (e.g., Folk et al., 1992) has shown that there is no cuing effect under these conditions. It remains to be seen whether processing is enhanced even when the theory predicts no cuing effect. 
Experiment 3 tests this by pairing motion and color singleton targets with a motion singleton cue. In previous work, Folk et al. (1994) have shown that motion singletons capture attention when the target is defined by motion, but not when targets are defined by color. In Experiment 3, the conditions of Folk et al. (1994) are combined with the compatibility manipulations used above. For one group of subjects, the motion cue is paired with a motion target (motion/motion condition). For the other group, the motion cue is paired with the color singleton target used in the previous experiments (motion/color). The contingent orienting account predicts capture and, hence, interference from incompatible items at the cued location only in the motion/motion condition. Since no capture is expected in the motion/color condition, this condition provides an important control for determining whether identity processing is associated with attention or the results of extraneous factors.

\section{Method}

Stimuli and Displays. The method follows closely that of Folk et al. (1994). The cue display was created by adding a set of four small white circles $\left(0.23^{\circ}\right)$ surrounding each location to the fixation display used in previous experiments. The cue itself was a 40$\mathrm{msec}, 45^{\circ}$ clockwise rotation of the set of circles surrounding one location. Target displays in Experiment 3 always contained the same four characters: the two target characters ( $\mathrm{L}$ and $\mathrm{T}$ ), one of which was the target, and the two neutrals (white E and F). In the motion/color condition, the target was the singleton red item among four white characters, as in the previous experiments. In the motion/motion condition, the target was the rotated item. The rotation used to indicate the target, like the motion cue, was a 40-msec rotation of $45^{\circ}$.

Subjects. The subjects were undergraduates from the Villanova University Psychology Human Subjects pool. Twenty-six participated in the motion/motion condition. A separate group of 16 subjects were tested in the motion/color condition. All had normal or corrected-to-normal visual acuity (20/35 or better). Ages ranged from 18 to 24 years. All received credit toward a research requirement for a general psychology course.

Procedure. Figure 5 shows the stimuli and sequence of events for the motion/motion condition. The fixation display was followed by a $120-\mathrm{msec}$ presentation of the cue display, composed of three 40 -msec segments. For the first $40 \mathrm{msec}$, the set of four circles surrounding each location were presented in canonical orientation. In the second $40 \mathrm{msec}$, the set of four circles around the cued location was rotated $45^{\circ}$. In the final $40 \mathrm{msec}$, the rotated set of circles was returned to its canonical orientation. The fixation display was presented again for $100 \mathrm{msec}$, followed by the target display. The target display consisted of three 40-msec segments, in the second of which the target was rotated $45^{\circ}$.

The subjects completed eight blocks of 50 trials, 10 practice trials followed by 40 experimental trials. Of the 40 experimental trials, 10 were target cue location trials (valid), 10 were foil cue location trials, and 20 were neutral cue location trials. On half the trials, the target was the T, on half the L. The design of Experiment 3 differed from the previous experiments in that all the target displays

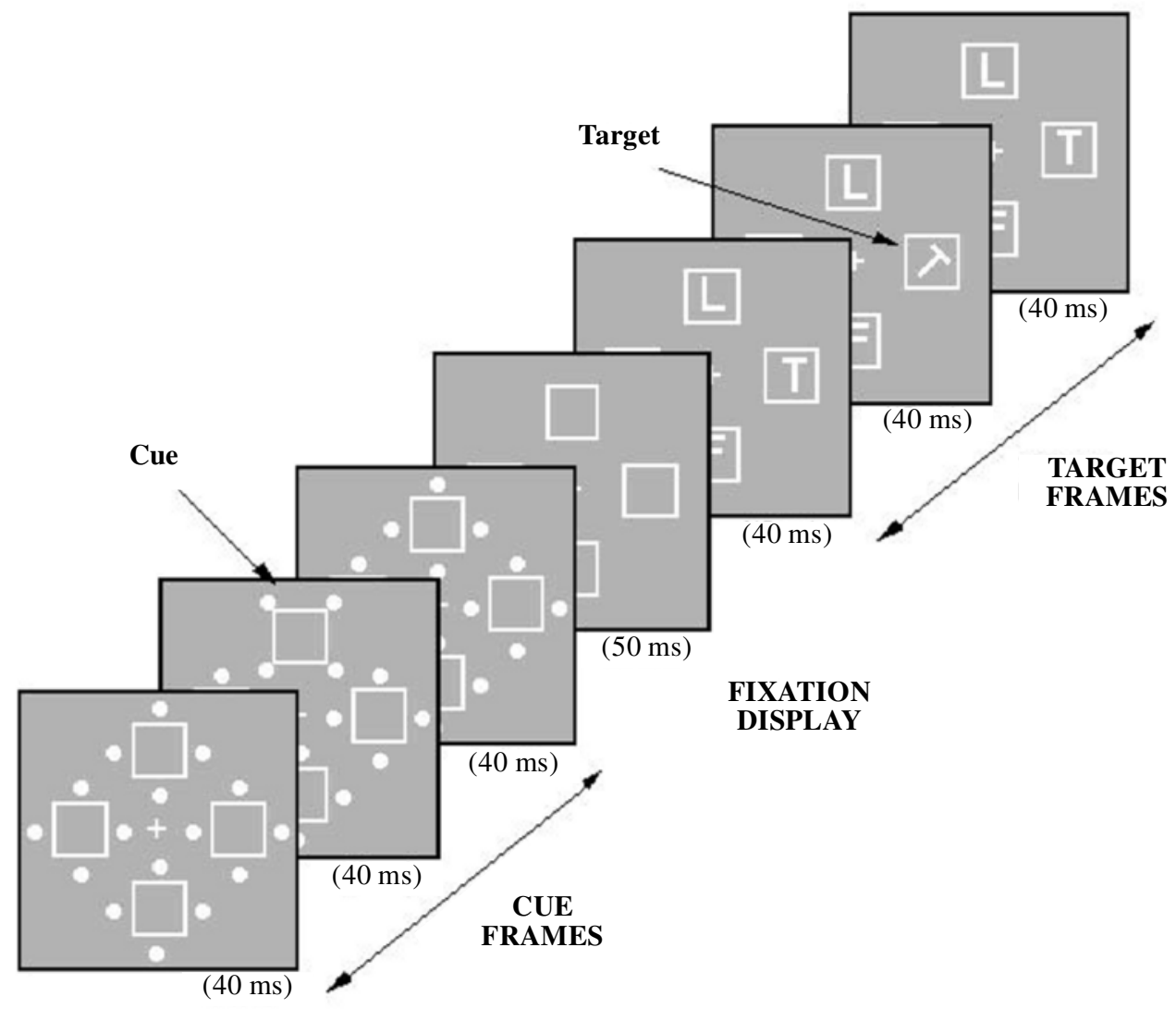

Figure 5. Stimulus displays and sequence of events for the motion/motion condition in Experiment 3. Target displays in the motion/color condition are the same as those in Experiments 1 and 2 (see Figures 1 and 2). 
contained an incompatible foil. Compatible and no-foil trials were eliminated.

\section{Results}

Motion/motion. Mean response times for motion targets in target, neutral, and foil conditions were 595, 635, and $645 \mathrm{msec}$, respectively. A one-way repeated measures ANOVA revealed a significanteffect of location $[F(2,50)=$ $31.02, p<.0001]$. Planned comparisons showed that the target response times were faster than the neutral response times $[F(1,25)=35.76, p<.001]$ and that the neutral response times were faster than the foil response times $[F(1,25)=4.35, p<.05]$.

Overall error rate was just over $13 \%$. Error rates for target, neutral, and foil cue locations were $9 \%, 12 \%$, and $19 \%$, respectively. An ANOVA showed the condition effect for errors to be significant $[F(2,50)=15.28, p<$ $.0001]$. A planned comparison test showed that the error rate in the foil condition was significantly greater than that in the neutral condition $[F(1,25)=14.14, p<.01]$.

Motion/color. Mean response times for target, neutral, and foil conditions were 529, 529, and $529 \mathrm{msec}$, respectively. The error rates in all the conditions were $2 \%$ or less.

\section{Discussion}

The predictions of the contingent involuntary orienting hypothesis were confirmed. Only the motion/motion condition showed the combination of a significant cuing effect coupled with interference from the incompatible foil when it occurred at the cued location. The motion/ color condition showed neither effect. The magnitude of the interference effect in the motion/motion condition was smaller than that in previous experiments. The difference between the neutral and the foil conditions, although significant, was only $10 \mathrm{msec}$. Elevated error rates for incompatible foils in the motion/motion condition are consistent with a speed-accuracy tradeoff whose effect would have contributed to reducing response times in that condition.

\section{GENERAL DISCUSSION}

\section{Contingent Involuntary Capture}

The experiments described here found a consistent pattern of interference from the identities of incompatible foil characters presented at the cued location when attention was captured by the cue. This pattern is evidence for an on-line allocation of attention in response to the cue, supporting the contingent involuntary orienting account of attentional capture. In keeping with contingent orienting, the effect of foil compatibility was observed only in the presence of a cuing effect resulting when cues and targets shared the target-finding property, either color or motion. In contrast, neither a cuing effect nor a compatibility effect was obtained when the targetfinding property was not present in the cue. The presence of a significant cuing effect accompanied by interference from incompatible characters at the cued location is strong evidence that attention was drawn on line to the cue in keeping with contingent orienting.

In contrast, no support was found for decision-level accounts, in which the cuing effect results from a delay in the allocation of attention on invalid trials because evidence for the target-finding property is present at two separate locations. In the delayed-allocation account, there is no capture of attention. Hence, there is no reason for the identities of characters at the cued location to be processed to a greater degree than those at other locations. We can reject the delayed-allocation account on the evidence that the identities of items incompatible with the target produce more interference when they occur at cued rather than noncued locations.

The presence of identity processing at cued locations is consistent with evidence from visual search (Theeuwes, 1996), suggesting that capture in the spatial cuing paradigm is not fundamentally different from that seen in visual search experiments. Instead, the results support the contention that costs and benefits used to infer capture in the spatial cuing paradigm are due to on-line allocation of processing resources also involved in shifting attention in visual search.

\section{Parallel Identity Processing}

Small compatibility effects at the neutral cue location suggested that the identity of the foil produced some interference when it occurred at a noncued location. This is especially pronounced at the 450-msec SOA of Experiment 1 . This observation is consistent with results from flanker studies (e.g., Eriksen \& Hoffman, 1973; Kramer \& Jacobson, 1991) in suggesting that attention is a "leaky" spatial filter, not tightly distributed around the attended region (see also Yantis \& Johnston, 1990). Alternatively, it is possible that with only four single alphanumeric characters, our displays produced a low perceptual load that promoted late selection (Lavie, 1995; Lavie \& Tsal, 1994; Yantis \& Johnston, 1990), allowing multiple characters to be identified. Whether the leaky filtering is on the input to identification (early selection) or the output (late selection), our main claim is unchanged. The empirical results clearly indicate substantially more interference when the incompatible character occurs at the cued location.

\section{REFERENCES}

Bundesen, C. (1990). A theory of visual attention. Psychological Review, 97, 523-547.

CAVE K. R. \& Wolf, J. M. (1990). Modelling the role of parallel processing in visual search. Cognitive Psychology, 22, 225-271.

ERIKSEN, C. W., \& Hoffman, J. E. (1973). The extent of processing of noise elements during selective encoding from visual displays. Perception \& Psychophysics, 14, 155-160.

Folk, C. L., \& Remington, R. W. (1996). When knowledge doesn't help: Limitations on the flexibility of attentional control. In A. F. Kramer, M. G. H. Cole, \& G. D. Logan (Eds.), Converging operations in the study of visual selective attention (pp. 271-295). Washington, DC: American Psychological Association.

Folk, C. L., \& Remington, R. W. (1998). Selectivity in distraction by irrelevant featural singletons: Evidence for two forms of attentional 
capture. Journal of Experimental Psychology: Human Perception \& Performance, 24, 847-858.

Folk, C. L., Remington, R. W., \& Johnston, J. C. (1992). Involuntary covert orienting is contingent on attentional control settings. Journal of Experimental Psychology: Human Perception \& Performance, 18, 1030-1044.

Folk, C. L., Remington, R. W., \& Johnston, J. C. (1993). Contingent attentional capture: A reply to Yantis (1993). Journal of Experimental Psychology: Human Perception \& Performance, 19, 682-685.

Folk, C. L., Remington, R. W., \& Wright, J. H. (1994). The structure of attentional control: Contingent attentional capture by apparent motion, abrupt onset, and color. Journal of Experimental Psychology: Human Perception \& Performance, 20, 317-329.

Kramer, A. F., \& Jacobson, A. (1991). Perceptual organization and focused attention: The role of objects and proximity in visual processing. Perception \& Psychophysics, 50, 267-284.

LAVIE, N. (1995). Perceptual load as a necessary condition for selective attention. Journal of Experimental Psychology: Human Perception \& Performance, 21, 451-468.

Lavie, N., \& Tsal, Y. (1994). Perceptual load as a major determinant of the locus of selection in visual attention. Perception \& Psychophysics, 56, 183-197.

Müller, H. J., \& RabbitT, P. M. A. (1989). Reflexive and voluntary orienting of visual attention: Time course of activation and resistance. Journal of Experimental Psychology: Human Perception \& Performance, 15, 315-330.

Posner, M. I. (1980). Orienting of attention. Quarterly Journal of Experimental Psychology, 32A, 3-25.

Remington, R. W., Johnston, J. C., \& Yantis, S. (1992). Involuntary attentional capture by abrupt onsets. Perception \& Psychophysics, $\mathbf{5 1}$ 279-290.

SPERLING, G. (1960). The information available in brief visual presentations. Psychological Monographs, 74 (11, Whole No. 498).

Theeuwes, J. (1991). Exogenous and endogenous control of attention: The effect of visual onsets and offsets. Perception \& Psychophysics, 49, 83-90.

Theeuwes, J. (1992). Perceptual selectivity for color and form. Perception \& Psychophysics, 51, 599-606.

Theeuwes, J. (1996). Perceptual selectivity for color and form: On the nature of the interference effect. In A. F. Kramer, M. G. H. Coles, \& G. D. Logan (Eds.), Converging operations in the study of visual selective attention (pp. 297-314). Washington, DC: American Psychological Association.
Theeuwes, J., \& Burger, R. (1998). Attentional control during visual search: The effect of irrelevant singletons. Journal of Experimental Psychology: Human Perception \& Performance, 24, 1342-1353.

Treisman, A., \& Sato, S. (1990). Conjunction search revisited. Journal of Experimental Psychology: Human Perception \& Performance, 16, 459-478.

Wolf, J. M., Cave, K. R. \& Franzel, S. L. (1989). Guided search: An alternative to the feature integration model for visual search. Journal of Experimental Psychology: Human Perception \& Performance, 15, 419-433.

Yantis, S., \& Egeth, H. E. (1999). On the distinction between visual salience and stimulus-driven attentional capture. Journal of Experimental Psychology: Human Perception \& Performance, 25, 661-676.

YAntis, S., \& HiLlstrom, A. P. (1994). Stimulus-driven attentional capture: Evidence from equiluminant visual objects. Journal of Experimental Psychology: Human Perception \& Performance, 20, 95-107.

YANTIS, S., \& Johnston, J. C. (1990). On the locus of visual selection: Evidence from focused attention tasks. Journal of Experimental Psychology: Human Perception \& Performance, 16, 135-149.

YANTIS, S., \& JonIDES, J. (1984). Abrupt visual onsets and selective attention: Evidence from visual search. Journal of Experimental Psychology: Human Perception \& Performance, 10, 601-621.

YANTIS, S., \& JonideS, J. (1990). Abrupt visual onsets and selective attention: Voluntary versus automatic allocation. Journal of Experimental Psychology: Human Perception \& Performance, 16, 121-134.

\section{NOTE}

1. We have conducted two replications of Experiment 1, using a fixed, 150-msec SOA. One was motivated by concern that the white background used for the boxes and distractor characters might allow the red of the cue to "bleed through," producing the sense of a desaturated red in the character at the cued location. To control for this, and to ensure that the specific color choices had no effect, we tested a new group of 16 subjects, using the red singletons of Experiment 1 as cue and target against a background of green distractors. The other replication used the motion/motion condition of Experiment 3 to generalize across cue types. Both experiments replicated the results presented here.

(Manuscript received July 12, 1999; revision accepted for publication April 27, 2000.) 